\title{
Hepatic Osteodystrophy- An overlooked complication
}

\author{
VivekKumar ${ }^{1}$, Sudhir Verma ${ }^{2}$, Ganesh Seth ${ }^{3}$, Nikhil P Joge ${ }^{4}$, Ravi Misra ${ }^{5}$ \\ ${ }^{1}$ Professor, Junior Grade, Department of Medicine, King George's Medical University, India \\ ${ }^{2}$ Assistant Professor, Department of Medicine, King George's Medical University, India \\ ${ }^{3}$ Senior Resident, Department of Cardiology, Sawai Man Singh Medical College, India \\ ${ }^{4}$ Senior Resident, Department of Medicine, King George's Medical college University, India \\ ${ }^{5}$ Professor and head, Department of Medicine, King George's Medical University, India
}

\begin{abstract}
Hepatic osteodystrophyis a metabolic bone disease commonly seen in patients with chronic liver disease (CLD). Osteoporosis\&osteomalaciadevelops in most of the patients with advanced liver disease. Regardless of the etiology of bone disease, such patients have an increased incidence of bone pain and fractures, a majorsource of morbidity.
\end{abstract}

Objectives -To study Bone mineral density (BMD) in patients of CLD and its correlation with severity of liver disease.

Material and methods: A cross sectional study was conducted in 64 patients with evidence of cirrhosis of liver. Out of these, 24 patients were alcoholic, 16 and 10 patients were suffering from hepatitis $B \& C$ respectively and no etiology was found in rest 14 patients. BMD of patients was analysed at different sites by DEXA scan and the prevalence of osteopenia and osteoporosis was noted. Severity of liver disease was assessed by Child Pugh's grading and compared with BMD.

Results: BMD was lower in most of the patients of CLD. High prevalence of osteopenia \& osteoporosis was observed at lumbar spine as compared to left hip, which was statistically significant in men(p<0.001) and women $(p<0.05)$. BMD was compared among different Child Pugh's severity grades, which showed high prevalence of osteopenia and osteoporosis in Child Pugh's grade C.

Keywords: Bone mineral density, chronic liver disease, hepatic osteodystrophy, osteoporosis, osteomalacia

\section{Introduction}

Metabolic bone diseases are common in patients of chronic liver disease(CLD) and are the major determinant of morbidity among these patients.Hepaticosteodystrophy $(\mathrm{HO})$ is a commonly associatedmetabolic bone disease in patients of CLD. Osteoporosis accounts for the majority of cases whereas osteomalacia is rare in the absence of advanced liver disease. Regardless of the etiology of bone disease, they have an increased incidence of bone pain and fractures, a major source of morbidity preceding and following liver transplantation ${ }^{[1]}$ Factors responsible for metabolic bone disease in patients ofCLD had been worked out in number of studies, but still remain unclear. Histologically, in hepatic osteodystrophy trabecular (cancellous) bone is more rapidly and severely affected than cortical bone ${ }^{[2]}$. However, numbers of mechanisms have been proposed for development of hepatic osteodystrophy. These mechanisms are malnutrition, hypogonadism (oestrogen and testosterone deficiency), vitamin D deficiency, osteprotegerin deficiency, alcoholism, hyperbilirubinemia, vitamin k deficiency, immunosuppressive drugs. Each of the mentioned factors is able to cause bone disease by itself, but in CLD patients, all of them acts synergistically to produce bone loss. ${ }^{[3-8]}$

Our study aims at determining the magnitude of bone loss in patients with chronic liver disease and to correlate the extent of bone loss with severity of liver dysfunction.

\section{Materials And Methods}

A cross sectional observational study was conducted in the department of Medicine, King George Medical University (KGMU),Lucknow,India over a period of one year (August 2011-July 2012). A total of sixty four patients were enrolled in the study.Patients with cirrhosis of liver with age between 18 to 50 years who were admitted in medical wards of KGMU,with evidence of hepatocellular dysfunction and portal hypertension, as evident by portal vein diameter $>13 \mathrm{~mm}$ on ultrasonography (USG) and presence of oesophageal varices by upper gastrointestinal endoscopy.Patients with age more than 50 years, renal disease, chronic obstructive pulmonary disease, post-menopausal women, pituitary and hypothalamic insufficiency and on drugs which alters bone densitywere excluded from our study

Detailed history and clinical examination was performed in all enrolled patients. Complete hemogram, random blood sugar, serum $\mathrm{Na}^{+}, \mathrm{K}^{+}$, blood urea, serum creatinine, urine examination, liver function tests (serum bilirubin, SGOT, SGPT, ALP, serum protein, serum albumin), prothrombin time, INR, viral markers(HIV, $\mathrm{HCV}, \mathrm{HBsAg}$ ) were carried out.Ultrasound whole abdomenwith special attention to portal vein diameter, echo- 
texture of liver, splenomegaly, ascites was performed by an expert radiologist.Upper gastrointestinal endoscopy, ascetic fluid examinationand Dual energy X-ray absorptiometry (DEXA) was done in all patients.

Results from a DEXA scan,analysed at left hip \& lumbar spine, were compared by two standards known as "age matched" or "young normal." The Z score is age-matched andT scorecompares the patient with the young normal reference mean. Based on T score, patient's bone density were categorised as normal, osteomalacia\& osteoporosis as shown in Table 1

Table 1.Assessment of BMD in adults

\begin{tabular}{|l|l|}
\hline & T-score \\
\hline Normal & +1 to -1 \\
\hline Osteomalacia & -1 to -2.5 \\
\hline Osteoporosis & Less than -2.5 \\
\hline
\end{tabular}

Severity of liver disease was assessed in patients by Child Pugh's classification.Bone mineral density was also compared among different grades of Child Pugh's classification.

\section{Results}

Based on inclusion criteria, sixty four patientswere enrolled in our study. Mean age of the study population was $39.9 \pm 6.5$ years, with 47 males \& 17 females. Out of $64,37 \%$ (24) patients were alcoholic, $25 \%$ (16) and $16 \%$ (10) patients were suffering from hepatitis B \& C respectively and no etiology was found in rest $22 \%$ (14) patients. Findings of BMD as obtained by DEXA scan is summarised as below.

Left hip: The results of BMD at left hip joint is summarised in Table-2.Bone density was lower in female patients as compared to male patients. Normal BMD was observed in $28 \%$ \& $31 \%$ of male \& female patients respectively. The prevalence of osteopenia was $57 \% \& 38 \%$ in male $\&$ female patients respectively while $15 \% \& 31 \%$ of male \&female patients respectively, were found to be osteoporotic.So, osteopenia was more common among males while osteoporosis more among female patients.

Table-2Distribution of bone density at left hip region

$X^{2}=2.64 ; p=0.27$

\begin{tabular}{|l|l|l|}
\hline & Male $(\mathrm{n}=47)$ & Female $(\mathrm{n}=17)$ \\
\hline Mean BMD $\left(\mathrm{mg} / \mathrm{cm}^{2}\right)$ & $854 \pm 181$ & $807 \pm 142$ \\
\hline Normal BMD $(\% / \mathrm{n})$ & $28 \%(13)$ & $31 \%(5)$ \\
\hline Osteopenia(\%/n) & $57 \%(27)$ & $38 \%(6)$ \\
\hline Osteoporosis $(\% / \mathrm{n})$ & $15 \%(7)$ & $31 \%(5)$ \\
\hline
\end{tabular}

Lumbar spine: The results of BMD at lumbar spine is summarised in Table-3.Bone density was lower in female patients as compared to male patients. None of the patients were found to have normal BMD. The prevalence of osteopenia was $40 \% \& 29 \%$ in male \& female patients respectively while $60 \%$ \& $71 \%$ of male $\&$ female patients respectively, were found to be osteoporotic.So,osteopenia was more common among males while osteoporosis more among female patients.

Table-3Distribution of bone mineral density at lumbar spine

\begin{tabular}{|l|l|l|l|}
\hline & Male $(\mathrm{n}=47)$ & Female $(\mathrm{n}=17)$ & \\
\hline $\begin{array}{l}\text { Meander } \\
\text { BMD }\left(\mathrm{mg} / \mathrm{cm}^{2}\right)\end{array}$ & $828 \pm 123$ & $821 \pm 104$ & $\mathrm{t}=0.21, \mathrm{p}>0.05$ \\
\hline Normal BMD & Nil & Nil & \\
\cline { 1 - 2 } Osteopenia $(\% / \mathrm{n})$ & $40 \%(19)$ & $29 \%(5)$ & \multirow{2}{*}{$\mathrm{X}^{2}=0.64 ; \mathrm{p}=0.42$} \\
\hline Osteoporosis $(\% / \mathrm{n})$ & $60 \%(28)$ & $71 \%(12)$ & \\
\hline
\end{tabular}

The results of BMD of both sites among males \& females are summarised in Table-4.High prevalence of osteopenia as well as osteoporosis was observed in patients with CLD.Maximum loss of BMD wasobserved at lumbar spine in both males \& females. The difference between BMD of both sites i.e. left hip and lumbar spine was highly $\operatorname{significant}(p<0.001)$ in male and significant $(p<0.05)$ in female patients.

Table-4Distribution of BMD among patients

\begin{tabular}{|l|l|l|l|l|}
\hline Gender & Males & Females \\
\hline Site & Left hip & LS spine & Left hip & LS spine \\
\hline Normal BMD $(\% / \mathrm{n})$ & $28 \%(13)$ & 0 & $31 \%(5)$ & 0 \\
\hline Osteopenia(\%/n) & $57 \%(27)$ & $40 \%(19)$ & $38 \%(6)$ & $29 \%(5)$ \\
\hline Osteoporosis $(\% / \mathrm{n})$ & $15 \%(7)$ & $60 \%(28)$ & $31 \%(6)$ & $71 \%(12)$ \\
\hline Left hip Vslumbar spine & $\mathrm{X}^{2}=26.99, \mathrm{p}<0.001$ & $\mathrm{X}^{2}=7.95, \mathrm{p}<0.05$ \\
\hline
\end{tabular}


Distribution of patients among different Child Pugh's gradeis summarised in Table-5

Table-5Distribution of patients in different Child Pugh's groups

\begin{tabular}{|l|l|l|}
\hline Child Pugh's grade & Number(n) & Percentage (\%) \\
\hline Grade B & 26 & $41 \%$ \\
\hline Grade C & 38 & $59 \%$ \\
\hline
\end{tabular}

Comparison of BMD among different Child Pugh's gradesis summarised in Table-6.Mean BMD decreases as the severity of liver disease and reduction in BMD was higher at lumbar spine as compared to left hip.

Table-6Distribution of mean BMD in different child pugh's groups

\begin{tabular}{|l|l|l|l|l|}
\hline Site & \multicolumn{2}{|c|}{ Left hip } & \multicolumn{2}{c|}{ Lumbar spine } \\
\hline Child Pugh's grade & Grade B & Grade C & Grade B & Grade C \\
\hline Mean BMD $\left(\mathrm{mg} / \mathrm{cm}^{2}\right)$ & $848 \pm 179$ & $837 \pm 168$ & $823 \pm 136$ & $818 \pm 105$ \\
\hline Group B vs C & \multicolumn{2}{|c|}{$\mathrm{t}=0.25, \mathrm{p}=0.78$} & $\mathrm{t}=0.18, \mathrm{p}=0.85$ \\
\hline
\end{tabular}

The prevalence of osteopenia as well as osteoporosis among different Child Pugh's grades is summarised in Table-7. Normal BMD was found in 35\% and $24 \%$ of patients at left hip in Child Pugh's grade B \& $\mathrm{C}$ respectively, however at lumbar region, none of the patient have normal BMD. Also, prevalence of osteoporosis as well as osteopenia was higher in Child Pugh's grade C than grade B.

Table-7Distribution of BMD among different child pugh's group

\begin{tabular}{|l|l|l|l|l|}
\hline Site & Left hip & \multicolumn{2}{|c|}{ Lumbar spine } \\
\hline Child Pugh's grade & Grade B & Grade C & Grade B & Grade C \\
\hline Normal BMD & $35 \%(9)$ & $24 \%(9)$ & NIL & NIL \\
\hline Osteopenia & $54 \%(14)$ & $50 \%(19)$ & $35 \%(9)$ & $32 \%(12)$ \\
\hline Osteoporosis & $11 \%(3)$ & $26 \%(10)$ & $65 \%(17)$ & $68 \%(26)$ \\
\hline Group B vs C & $X^{2}=2.36 ; \mathrm{p}=0.31$ & $\mathrm{X}^{2}=0.15 ; \mathrm{p}=0.69$ \\
\hline
\end{tabular}

\section{Discussion}

Various factors responsible for causing metabolic bone disease in patients with CLD have been worked out in number of studies and but are still remains unclear.VitaminDdeficiency is the most important mechanism proposed for development of metabolic bone disease in cirrhosis of liver. Decreased level of vitamin D in patients with cirrhosis of liver can be due to decreased intake, decreased absorption from gut, decreased synthesis \& increased urinary loss.Osteprotegerin(OPG)a member of the tumour necrosis factor receptor superfamily has recently been found to regulate boneturnover. OPG,produced by liver, inhibits osteoclast differentiation. In a transgenic mice model, increased hepatic expression of OPG resulted in osteopetrosis, or increased bone density. The role of OPG in hepatic osteodystrophy is speculative; a decline in liver function may be associated with reduced production of OPG and increased osteoclast-mediated bone resorption. ${ }^{[9]}$

Alcoholism itself is an independent risk factor for development of bone diseases as long-term alcohol consumption can interfere with bone growth and replacement of bone tissue (i.e., remodelling), resulting in decreased bone density and increased risk of fracture. These effects may be exerted directly or indirectly through the many cell types, hormones, and growth factors that regulate bone metabolism. ${ }^{[10]}$

The pathogenesis behind decreased bone density in CLD was given in a review article by I A Nakchbandi in which he explained the pathogenic mediators like fibronectin, insulin like growth factor-I, and various cytokines like RANK L are depleted in patients of CLD which causes depletion of bone density in patients of CLD. ${ }^{[11]}$

As a result of all of the above pathological processes occurring in patients with CLD, there is reduced BMD in these patients resulting increased incidences of bone pains and sometimes bone fractures in CLD patients.Similarly even in our study, we found that BMD was lower in most of the patients of CLD. DEXA scan results in these patients showed high prevalence of osteopenia as well as osteoporosis. BMD was lower in females as compared to male patients. Similar findings were also seen in study done by Turkeli $\mathrm{M}_{\text {et al }}{ }^{[12]}$ showedthat among 40 patients the prevalence of osteopenia and osteoporosis is $45 \%$ and $42.5 \%$ respectively. Another study conducted by Sokhi et al ${ }^{[13]}$ suggested among 104 cirrhotic patients, prevalence of osteopenia and osteoporosis were $34.6 \%$ and $11.5 \%$ respectively being significantly higher in females. Auletta et al [14] conducted study among 30 patients of chronic viral hepatitis and found that the prevalence of osteopenia and osteoporosis were $44 \%$ and $20 \%$ respectively.

Bone mineral densities were compared between left hip and lumbar spine, we found that there was high prevalence of osteopenia and osteoporosis at lumbar spine as compared to left hip which was significant. Similar findings were also seen in study done by Turkeli $\mathrm{M}$ et al ${ }^{[12]}$, Sokhi et al ${ }^{[13]}$ and George $\mathrm{J}$ et al ${ }^{[15]}$ in which 
lumbar spine is severely affected than left hip. The probable reason behind the same findings is due to faster renewal oftrabecularbone rate than cortical bone, sites with a high proportion of trabecular bone, such as vertebrae and hips, will be affected earliest. However, vertebrae consist of 50\% trabecular bone and the femoral neck consists of $30 \%$ trabecular bone, thus, changes in BMD will be apparent earlier and with more severity in the lumbar spine than at the femoral neck. The differences in bone composition between the lumbar spine and the femoral neck can therefore explain the differences in BMD found between these sites. ${ }^{[16]}$

BMD decreases as the severity of liver disease increases. This was also supported by Turkeli M et al ${ }^{[12]}$, Sokhi et al ${ }^{[13]}$ and Giouleme OI et al ${ }^{[17]}$ which showreduction in BMD with the severity of liver disease.

\section{Conclusion}

Our study suggested that CLD is associated with high prevalence of osteopenia \&osteoporosis, leading to increased morbidity \& mortality.Most of such patients are asymptomatic \& later present with complications.So, all patients of CLD should be screened for assessment of BMD to rule out hepatic osteodystrophy, so that early diagnosis \& timely intervention can be done.

\section{References}

[1]. RouillardS; hepatic osteodystrophy;J. Hepatology:January 2001:301

[2]. Diamond TH, Stiel D, Lunzer M, McDowall D, Eckstein RP, Posen S.Hepaticosteodystrophy. Static and dynamic bone histomorphometryand serum bone Gla-protein in 80 patients with chronic liver disease.Gastroenterology 1989;96:213-221.

[3]. Matloff DS, Kaplan MM, Neer RM, Goldberg MT, Bitman W, Wolfe HJ.Osteoporosis in primary biliary cirrhosis: effects of 25hydroxyvitamin Dtreatment. Gastroenterology 1982;83:97-102.

[4]. Lalor BC, France MW, Powell D, Adams PH, Counichan TB. Bone andmineral metabolism and chronic alcohol abuse. QJ Med 1986;59:497-511.

[5]. Janes CH, Dickson ER, Okazaki R, Bonde S, McDonagh AF, Riggs BL.Role of hyperbilirubinemia in the impairment of osteoblast proliferationassociated with cholestatic jaundice. J Clin Invest 1995;95:2581-2586.

[6]. Pignata S, Daniele B, Galati MG, Esposito G, Vallone P, Fiore F, RicchiP,et al. Oestradiol and testosterone blood levels in patients with viral cirrhosisand hepatocellular carcinoma. Eur J GastroenterolHepatol 1997;9:283-286.

[7]. Simonet WS, Lacey DL, Dunstan CR, Kelley M, Chang MS, LuthyR,Nguyen HQ, et al. Osteoprotegerin: a novel secreted protein involved inthe regulation of bone density. Cell 1997;89:309-319.

[8]. Bell H, Raknerud N, Falch JA, Haug E. Inappropriately low levels ofgonadotrophins in amenorrhoeic women with alcoholic and non-alcoholiccirrhosis. Eur J Endocrinol 1995;132:444-449.

[9]. Simonet WS, Lacey DL, Dunstan CR, Kelley M, ChangMS, Lüthy R, et al. Osteoprotegerin: a novel secreted protein involved in the regulation of bone density. Cell1997;89:309-19.

[10]. Sampson HW. Alcohol's harmful effects on bone. Alcohol Health Res World. 1998;22(3):190-4.

[11]. Inaam A Nakchbandi. Osteoporosis and fractures in liver disease: Relevance, pathogenesis and therapeutic implications. World $\mathbf{J}$ Gastroenterol. 2014 Jul 28; 20(28): 9427-9438.

[12]. Mehmet Turkeli, HakanDursun, FatihAlbayrak, NihatOkçu, M. HamidullahUyanik, Abdullah Uyanik, RahşanYıldırım, Mustafa Keleş,Omer Yılmaz. Effects of Cirrhosis on Bone Mineral Density and Bone Metabolism.Eurasian J Med. 2008 Apr; 40(1): 18-24

[13]. Sokhi RP, Anantharaju A, Kondaveeti R, Creech SD, Islam KK, Van Thiel DH. Bone mineral density among cirrhotic patients awaiting liver transplantation. Liver Transpl. 2004;5:648-53.

[14]. Auletta M, Nuzzo V, Esposito A, Antoniello S, Fonderico F, Lupoli G. Osteoporosis in men: a study in patients affected by chronic non-advanced liver disease. Clin Cases Miner Bone Metab2005;2:25-28.

[15]. George J, Ganesh HK, Acharya S, Bandgar TR, Shivane V, Karvat A, Bhatia SJ, Shah S, Menon PS, Shah N. Bone mineral density and disorders of mineral metabolism in chronic liver disease. World J Gastroenterol2009; 15:3516-3522.

[16]. Kalef-Ezra JA, Merkouropoulos MH, Challa A, Hatzikonstantinou J, Karantanas AH, Tsianos EV. Amount and composition of bone minerals in chronic liver disease. Dig Dis Sci. 1996;41:1008-13.

[17]. Giouleme OI, Vyzantiadis TA, Nikolaidis NL, Vasiliadis TG, Papageorgiou AA, Eugenidis NP, et al. Pathogenesis of osteoporosis in liver cirrhosis. Hepatogastroenterology. 2006;53(72):938-43. 